\title{
ARTICLE
}

Acute myeloid leukemia

\section{Selective recruitment of $\gamma \delta$ T cells by a bispecific antibody for the treatment of acute myeloid leukemia}

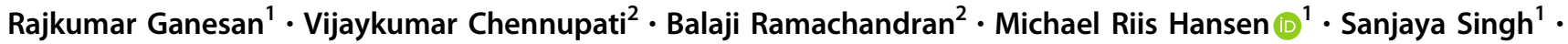 \\ lqbal S. Grewal (1)
}

Received: 9 March 2020 / Revised: 19 November 2020 / Accepted: 7 January 2021 / Published online: 1 February 2021

(c) The Author(s), under exclusive licence to Springer Nature Limited 2021. This article is published with open access

\begin{abstract}
Despite significant progress over the last few decades in the treatment of acute myeloid leukemia (AML), there still remains a major unmet medical need for this disease. Immunotherapy approaches for redirecting pan $\mathrm{CD}^{+} \mathrm{T}$ cells to target leukemia blasts have shown limited efficacy in clinical trials and often accompanied with severe toxicity in AML patients. We designed an alternative engager molecule (Anti-TRGV9/anti-CD123), a bispecific antibody that can simultaneously bind to the $\mathrm{V} \gamma 9$ chain of the $\mathrm{V} \gamma 9 \mathrm{~V} \delta 2^{+} \gamma \delta \mathrm{T}$ cell receptor and to AML target antigen, $\mathrm{CD} 123$, to selectively recruit $\mathrm{V} \gamma 9^{+} \gamma \delta \mathrm{T}$ cells rather than pan $\mathrm{T}$ cells to target AML blasts. Our results suggest that prototypic bispecific antibodies (a) selectively activate $\mathrm{V} \gamma 9^{+} \gamma \delta \mathrm{T}$ cells as judged by CD69 and CD25 surface expression, and intracellular Granzyme B expression, (b) selectively recruit $\mathrm{V} \gamma 9^{+} \gamma \delta \mathrm{T}$ cells into cell-cell conjugate formation of $\gamma \delta \mathrm{T}$ cells with tumor cells indicating selective and effective engagement of effector and target tumor cells, and (c) mediate $\gamma \delta \mathrm{T}$ cell cytotoxicity (in vitro and in vivo) against tumor antigen-expressing cells. Collectively, these findings suggest that selectively redirecting $\mathrm{V} \gamma 9^{+} \gamma \delta \mathrm{T}$ cells to target AML blasts has a potential for immunotherapy for AML patients and favors further exploration of this concept.
\end{abstract}

\section{Introduction}

Acute myeloid leukemia (AML) is a fast-growing disease that occurs in large, immature white blood cells leading to leukemia [1]. Chemotherapy and hematopoietic stem cell transplantation are some treatments options; however, ineligible patients survive only for less than a year [2,3]. As the role of $\mathrm{T}$ cells in the anti-cancer immune response is strongly supported and correlates with a favorable clinical prognosis in many cancers [4], novel strategies to redirect $\mathrm{T}$ cells for immunotherapy have been increasingly investigated for multiple cancers including AML [5-8]. Two different strategies, chimeric antigen receptor (CAR) T cells

Supplementary information The online version contains supplementary material available at https://doi.org/10.1038/s41375021-01122-7.

Iqbal S. Grewal

igrewal@its.jnj.com

1 Janssen Biotherapeutics, The Janssen Pharmaceutical Companies of Johnson \& Johnson, Ambler, PA, USA

2 Syngene International Ltd., Bangalore, India and bispecific protein therapeutics to recruit $\mathrm{CD}^{+} \mathrm{T}$ cells to kill tumor cells, are currently being explored in clinical trials. Although redirecting T cells via CD3 is attractive, it raises two key concerns: (i) indiscriminate stimulation of pan- $T$ cells including various immunoregulatory and immunosuppressive $\mathrm{T}$ cells, which play an active role in immune evasion and (ii) overt pan $\mathrm{T}$ cell activation that can lead to cytokine storm resulting in severe side effects. To alleviate some of these limitations, an alternative strategy would be to selectively redirect only cytotoxic cells rather than indiscriminately stimulate pan-T cells.

Recently, $\gamma \delta \mathrm{T}$ cells have emerged as a great player in the cancer immunotherapy field $[9,10]$. Although $\gamma \delta$ T cells are $\sim 5 \%$ of human peripheral blood $\mathrm{T}$ cells, they are the majority in epithelial tissues (lung, gut, and genital tract) [11] and display both innate and adaptive characteristics [12]. In addition, $\gamma \delta \mathrm{T}$ cells have been shown to infiltrate cancers and positively correlate with favorable clinical outcome [4]. In adults, 50 to $>95 \%$ of blood $\gamma \delta \mathrm{T}$ cells usually express a TCR encoded by V $\gamma 9$ and V $\delta 2$ chains, and are endowed with potent anti-cancer functions $[8,13]$. Interestingly, anti-V $\gamma 9 / \mathrm{V} \delta 2 \mathrm{TCR}$ antibodies that bind to $\mathrm{V} \gamma 9$ or $\mathrm{V} \delta 2$ chain were shown to activate these $\gamma \delta \mathrm{T}$ cells $[14,15]$, suggesting that anti-TCR-based redirecting 
molecules can be constructed to redirect $\mathrm{V} \gamma 9 / \mathrm{V} \delta 2^{+} \mathrm{TCR} \gamma \delta$ $\mathrm{T}$ cell subset for tumor elimination. Non-Fc scaffold-based bispecific antibodies with tumor targets such as Her2/EGFR were described recently $[9,10,15]$. Thus, approaches that help to overcome the limitations of CD3-based redirection and avoid pan activation of $\mathrm{T}$ cells can be designed to induce potent tumor cell lysis by selectively recruiting $\gamma \delta$ $\mathrm{T}$ cells.

In the present study, we designed and characterized a bispecific antibody, anti-TRGV9/anti-CD123, that can simultaneously bind to the $\mathrm{V} \gamma 9$ chain of the $\gamma \delta \mathrm{T}$ cell receptor and to CD123. CD123 is a validated target antigen expressed abundantly on AML blasts, and on CD34 ${ }^{+} / \mathrm{CD} 38^{-}$leukemic stem cells, and thus provides an opportunity to target malignant cells. Our results presented in this report suggest that selectively redirecting $\mathrm{V} \gamma 9^{+} \gamma \delta \mathrm{T}$ cells to target AML blasts has a potential for immunotherapy for AML patients.

\section{Materials and methods}

Blood collection, isolation of PBMCs, expansion of $\mathrm{V} \gamma 9^{+}$ $\gamma \delta \mathrm{T}$ cells, tumor cell lines and reagents, flow cytometer methods, statistical analysis, and engineering of the bispecific antibodies are described in the Supplementary information.

\section{Bispecific antibody binding assay}

Binding of anti-TRGV9/CD123 (V $\gamma 9 / \mathrm{CD} 123)$ and antiTRGV9/ Null (V $\gamma 9 /$ Null) bispecific antibodies to CD123expressing cell lines and $\gamma \delta \mathrm{T}$ cells was carried out by flow cytometry. Briefly, cells were stained with bispecific antibodies and detected by labelled mouse anti-human IgG1 or IgG4 secondary antibody (SouthernBiotech, Birmingham, and $\mathrm{AL}$ ), and the fluorescence of stained cells was measured on a flow cytometer.

\section{Cell-cell conjugate formation assay}

Enriched effector cells ( $\gamma \delta$ T cells) and target cells (Kasumi3) were labelled with $0.3 \mu \mathrm{M}$ CellTracker ${ }^{\mathrm{TM}}$ Green CMFDA and $1.5 \mu \mathrm{M}$ CellTracker ${ }^{\mathrm{TM}}$ Orange CMRA (Life Technologies, Carlsbad, CA) dyes, respectively. $1.0 \times 10^{5}$ cells $/ \mathrm{mL}$ labelled cells of each were co-cultured in the presence or absence of specified bispecifics at a concentration of $1 \mu \mathrm{g} /$ $\mathrm{mL}$ and incubated at $37^{\circ} \mathrm{C}, 5 \% \mathrm{CO}_{2}$ for $1 \mathrm{~h}$ one hour. Cells were fixed by incubating them with $\mathrm{BD}$ Cytofix (BD Biosciences, San Jose, CA) for $15 \mathrm{~min}$ at $4{ }^{\circ} \mathrm{C}$ and analyzed on flow cytometer. FlowJo analysis software (Treestar Inc, Ashland, OR) was used to analyze cell-cell conjugate formation. Cells engaged in cell-cell conjugate formation can be visualized on FACS plots as cells positive for both cell tracker green and cell tracker orange dyes.

\section{In vitro cytotoxicity assay using enriched $\gamma \delta \mathrm{T}$ cells}

Enriched $\gamma \delta \mathrm{T}$ cells (Effectors (E)) were co-cultured with CFSE-labelled Kasumi-3 cells (Targets (T)) at different E:T ratios in the presence of various concentrations of the bispecific antibodies for $24 \mathrm{~h}$. At the end of the incubation period, 7-AAD (7-Aminoactinomycin D) (BioLegend, San Diego, CA) was added to the culture and cells were analyzed by a flow cytometer. Dead target cells were identified as 7-AAD ${ }^{+}$FSC $^{\text {low }}$ cells. To calculate bispecific antibodymediated specific killing, cell lysis value from no bispecific antibody control was subtracted from the total cell death value obtained from the indicated bispecific antibodies. The spontaneous cytotoxicity of target cells was assessed by culturing them without effector cells or bispecific antibodies. $\mathrm{EC}_{50}$ was calculated using a 4-parameter doseresponse curve with the concentration on the $x$-axis (log scale) and specific lysis on the $y$-axis (linear scale) using GraphPad Prism version 8.2.1 (La Jolla, CA). Log values on the $x$-axis were converted into anti-log values for representation purpose.

\section{In vitro activation, proliferation, and cytotoxicity assays using whole blood PBMCs}

Briefly, CFSE-labelled PBMCs $\left(0.1-0.2 \times 10^{6}\right.$ cells $)$ were spiked in with 10,000 Kasumi-3 cells (at a ratio of 1:1 $\mathrm{V} \gamma 9^{+}$ $\gamma \delta \mathrm{T}$ cells and Kasumi- 3 cells) and cultured in the absence or presence of indicated bispecific antibodies. Activation and proliferation of $\mathrm{V} \gamma 9^{+} \gamma \delta \mathrm{T}$ cells were assessed by measuring the surface expression of CD69, CD25, and CFSE dilution, respectively, on day 3. For assessing bispecific mediated $\mathrm{V} \gamma 9^{+} \gamma \delta$ T cell cytotoxicity, PBMCs were spiked in with CFSE-labelled Kasumi-3 cells and cultured in the presence of the indicated bispecific antibodies. Elimination of Kasumi-3 cells (\% 7-AAD ${ }^{+}$cells among $\mathrm{CFSE}^{+}$Kasumi- 3 cells), as a measure of cytotoxicity, was measured on day 5 of the culture. Bispecific mediated $\mathrm{V} \gamma 9^{+}$ $\gamma \delta$ T cells' specific cytotoxicity was calculated by deducting the basal cytotoxicity, as described in the above sections. Procedures for AML patient-derived PBMCs are described in the Supplementary information.

\section{Cytokine and effector molecule analysis}

For intracellular cytokine and effector molecules' assessment, cells were initially surface stained with the indicated monoclonal antibodies, fixed, and permeabilized using BD Fix/Perm kit (BD Biosciences, San Jose, CA) as per the manufacturer's instructions. Permeabilized cells were 
probed with monoclonal antibodies against intracellular cytokines (TNF $\alpha$, IFN $\gamma$ ) or effector molecules (Granzyme $\mathrm{B}$, Perforin) for $30 \mathrm{~min}$ at $4{ }^{\circ} \mathrm{C}$. Cells were acquired on a flow cytometer. For assessing the cytokines, culture supernatants were collected at the indicated time points and subjected to quantification using a customized human magnetic Luminex assay 15 plex kit (R\&D systems, Minneapolis, USA), as per the manufacturer's instructions. Quantification of the cytokines was carried out in a MagPix multiplex detection system with xPONENT software (version 4.2).

\section{Xenograft tumor model and imaging of $\gamma \delta \mathrm{T}$ cells}

The in vivo efficacy of the $\mathrm{V} \gamma 9 / \mathrm{CD} 123$ bispecific antibody was analyzed using a xenograft mouse model, as reported earlier with minor modifications [9, 16-19]. Detailed description of the experimental procedure for efficacy and imaging study is available in the Supplementary information.

\section{Results}

\section{$\mathrm{V} \mathbf{9}^{+} \mathrm{\gamma} \delta \mathrm{T}$ cells are suitable as effector cells for redirection}

We focused our studies on circulating $\gamma \delta \mathrm{T}$ cells that express heterodimers of $\mathrm{V} \gamma 9 / \mathrm{V} \delta 2$ TCR chains because they manifest potent anti-cancer functions [20]. The frequency of circulating $\mathrm{V} \gamma 9^{+} \gamma \delta \mathrm{T}$ cells in the blood ranged from $\sim 1$ to $15 \%$ of total $\mathrm{CD}^{+} \mathrm{T}$ cells (Supplementary Fig. S1a), with an average of $\sim 4 \%$ of $\mathrm{V} \gamma 9^{+} \gamma \delta \mathrm{T}$ cells among the total $\mathrm{T}$ cells (Supplementary Fig. S1b). We further characterized the phenotype of $\mathrm{V} \gamma 9^{+} \gamma \delta \mathrm{T}$ cells by stimulating them with Zoledronic acid that selectively expands and activates $\mathrm{V} \gamma 9^{+} \gamma \delta \mathrm{T}$ cells from whole PBMCs. Majority of the $\mathrm{V} \gamma 9^{+} \gamma \delta \mathrm{T}$ cells present in fresh PBMCs are either central memory (CD27+, CD45RA-) or effort memory (CD27-, CD45RA-) whereas activated cells develop into effector memory cells $\left(\mathrm{CD} 27^{-}, \mathrm{CD}^{2} 4 \mathrm{RA}^{-}\right)$, express high levels of intracellular Granzyme B and Perforin, and upregulate expression of activation markers (Supplementary Fig. S1c-e). Collectively these data suggest that abundance of $V \gamma 9^{+} \gamma \delta \mathrm{T}$ cells in the circulation and phenotype of activated $V \gamma 9^{+} \gamma \delta \mathrm{T}$ cells is appropriate for redirecting these cells to kill tumor cells. We observed upregulation of some exhaustion markers on activated $\mathrm{V} \gamma 9^{+} \gamma \delta \mathrm{T}$ cells (Supplementary Fig. S1f). However, these cells are perfectly functional (see the following sections) and show robust activity. Moreover, it is yet to be determined if the traditional markers of exhaustion apply to $\gamma \delta \mathrm{T}$ cells. It is still possible that these activated cells may become exhausted and we need to use caution in interpreting these data. Indeed, if exhaustion markers are expressed, then it opens the potential for synergy with anti-checkpoint inhibitors.

\section{Anti-TRGV9/anti-CD123 (Vy9/CD123) bispecific antibody selectively binds to $V \gamma 9^{+} \gamma \delta \mathrm{T}$ cells and CD123-expressing tumor cells}

$\mathrm{V} \gamma 9 / \mathrm{CD} 123$ bispecific antibody was designed to recruit $\mathrm{V} \gamma 9^{+}$ $\mathrm{T}$ cells to kill tumor cells as shown in Fig. 1a (also see Supplementary Fig. S2). Binding of bispecific antibodies to $\mathrm{V} \gamma 9^{+}$ $\gamma \delta \mathrm{T}$ cells and CD123 expressing tumor cells (Kasumi-3, MOLM-13, and KG-1) was assessed; the data presented in Fig. $1 \mathrm{~b}$ indicate binding of both $\mathrm{V} \gamma 9 / \mathrm{CD} 123$ and $\mathrm{V} \gamma 9 / \mathrm{Null}$ control bispecific antibodies to $\mathrm{V} \gamma 9^{+} \gamma \delta \mathrm{T}$ cells. We further determined if $\mathrm{V} \gamma 9 / \mathrm{CD} 123$ bispecific antibody selectively binds to $\mathrm{V} \gamma 9^{+} \gamma \delta \mathrm{T}$ cells by depleting $\mathrm{V} \gamma 9^{+} \gamma \delta \mathrm{T}$ cells from enriched pan-T cells obtained from whole PBMCs and measuring the binding. Our data show the lack of binding of $\mathrm{V} \gamma 9 / \mathrm{CD} 123$ and null control bispecific antibodies to pan- $\mathrm{T}$ cells that were devoid of $\mathrm{V} \gamma^{+}$cells (Supplementary Fig. S3a). Similarly, we determined binding of $\mathrm{V} \gamma 9 / \mathrm{CD} 123$ bispecific antibody to tumor cells; the data presented in Fig. 1c show binding of the $\mathrm{V} \gamma 9 / \mathrm{CD} 123$ bispecific antibody to CD123-expressing Kasumi-3, MOLM-13, and KG-1 tumor cells. Collectively, these data indicate that bispecific antibodies are suitable for recruiting $\mathrm{V} \gamma 9^{+} \gamma \delta \mathrm{T}$ cells to eliminate CD123-expressing target cells.

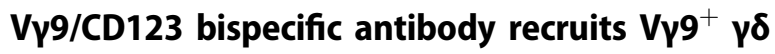 $T$ cells into biphasic cell-cell conjugate formation with tumor cells}

In order to determine if $\mathrm{V} \gamma 9 / \mathrm{CD} 123$ bispecific antibody recruits $\mathrm{V} \gamma 9^{+} \gamma \delta \mathrm{T}$ cells into biphasic cell-cell conjugate with target cells, $\gamma \delta \mathrm{T}$ cells (effector cells) and Kasumi-3 (Targets) cells were co-cultured in the presence of bispecific antibodies $(\mathrm{V} \gamma 9 / \mathrm{CD} 123$ and $\mathrm{V} \gamma 9 / \mathrm{Null})$ and analyzed for conjugation formations. Data presented in Fig. 2a show that $\mathrm{V} \gamma 9 / \mathrm{CD} 123$ bispecific antibody mediated conjugation formation between $\mathrm{V} \gamma 9^{+} \gamma \delta \mathrm{T}$ cells and CD123-expressing tumor cells, similar to the conjugation formation by antiCD3/anti-CD123 (CD3/CD123) bispecific antibody. Taken together, these data suggest effective conjugation formation between effector and targets cells that is prerequisite for $\mathrm{T}$ cell-mediated cytotoxicity.

\section{Vy9/CD123 bispecific antibody selectively activates $V_{\gamma} 9^{+} \gamma \delta T$ cells}

To determine selective activation of $\mathrm{V} \gamma 9^{+} \gamma \delta \mathrm{T}$ cells and induction of their cytotoxicity, we utilized a two cell coculture system where enriched pan-T cells were co-cultured with Kasumi-3 cells at an ET ratio of 1:1 in the presence of 
a.

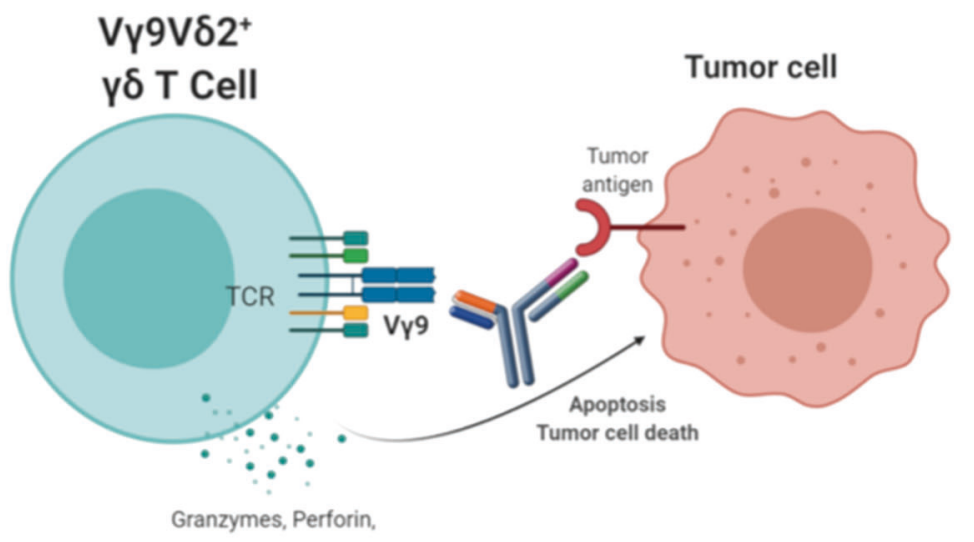

C.

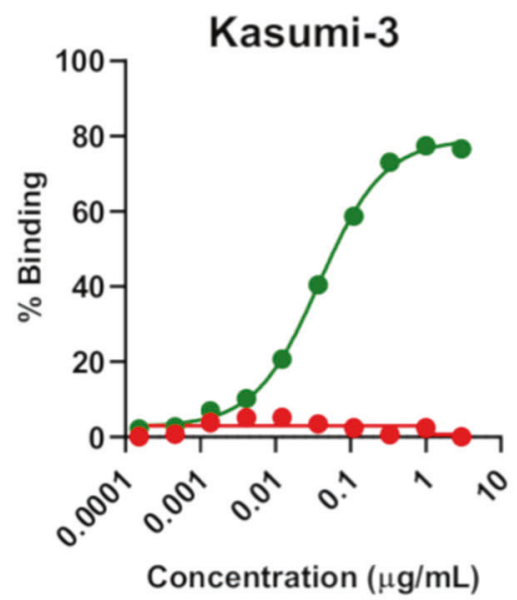

b.

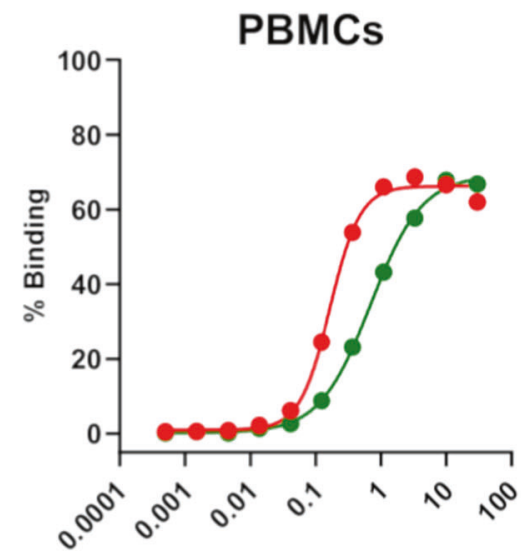

Concentration $(\mu \mathrm{g} / \mathrm{mL})$

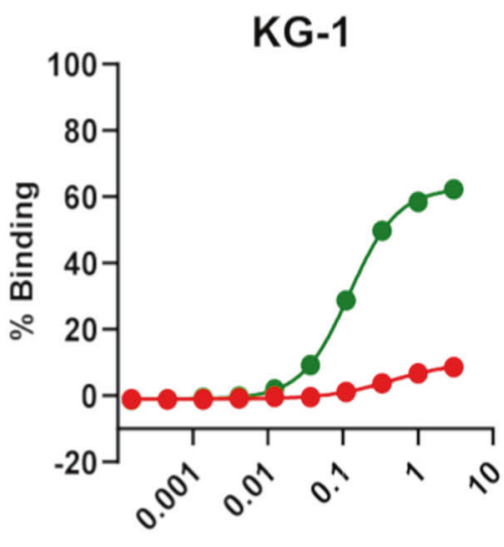

Concentration $(\mu \mathrm{g} / \mathrm{mL})$

\section{V $\gamma 9 / C D 123$ bispecific}

Fig. 1 Mechanism of action and binding of anti-TRGV9/antiCD123 (V $\gamma$ 9/CD123) bispecific antibody to $V \gamma 9^{+} \gamma \delta \mathrm{T}$ cells and CD123-expressing tumor cells. a Bispecific antibody bridges the tumor to T cells and assists with the establishment of immune synapse, leading to the release of cytolytic agents such as perforin. Binding of bispecific antibodies to PBMCs (b) that were activated and expanded with Zoledronic acid+IL-2+IL-15 for 14 days and (c) CD123-

bispecific antibody. To serve as positive and negative control, co-cultured cells were also stimulated with CD3/CD123 and $\mathrm{V} \gamma \mathrm{9} / \mathrm{Null}$ bispecific antibodies. At the end of the culture period, the frequency of $\mathrm{V} \gamma 9^{+}$and $\mathrm{V}_{\gamma} 9^{-} \gamma \delta \mathrm{T}$ cells (also includes $\mathrm{CD} 4^{+}$and $\mathrm{CD} 8^{+} \alpha \beta \mathrm{T}$ cells) positive for activation markers, CD69, CD25, and CD71 surface expression (Fig. 2b) and intracellular Granzyme B expression (Fig. 2c) and proliferation (Fig. 2d) was determined. Our data demonstrate that $\mathrm{V} \gamma 9 / \mathrm{CD} 123$ bispecific antibody selectively activates and mediates proliferation of only $\mathrm{V} \gamma 9^{+} \gamma \delta \mathrm{T}$ cells, whereas CD3/CD123 bispecific antibody affects pan-T cells and mediates their activation.

\section{VY9/CD123 bispecific antibody efficiently mediates cytotoxicity induced by $\mathrm{V} \mathrm{9}^{+} \mathrm{\gamma} \delta \mathrm{T}$ cells}

$\mathrm{V} \gamma 9^{+} \gamma \delta \mathrm{T}$ cells (effectors) that were expanded from PBMCs in vitro were co-cultured with either Kasumi-3 cells or MOLM-13 or KG-1 cells (targets) in the presence of various concentrations of the bispecific antibodies, and cytotoxicity of the target cells was determined as described in "Materials and methods". Our data show that $\mathrm{V} \gamma \mathrm{g} /$ CD123 bispecific antibody mediates $\mathrm{V} \gamma 9^{+} \gamma \delta \mathrm{T}$ cell cytotoxicity against CD123-expressing kasumi-3, MOLM-13, and KG-1 cells in a dose-dependent manner (Fig. 3a-c). 

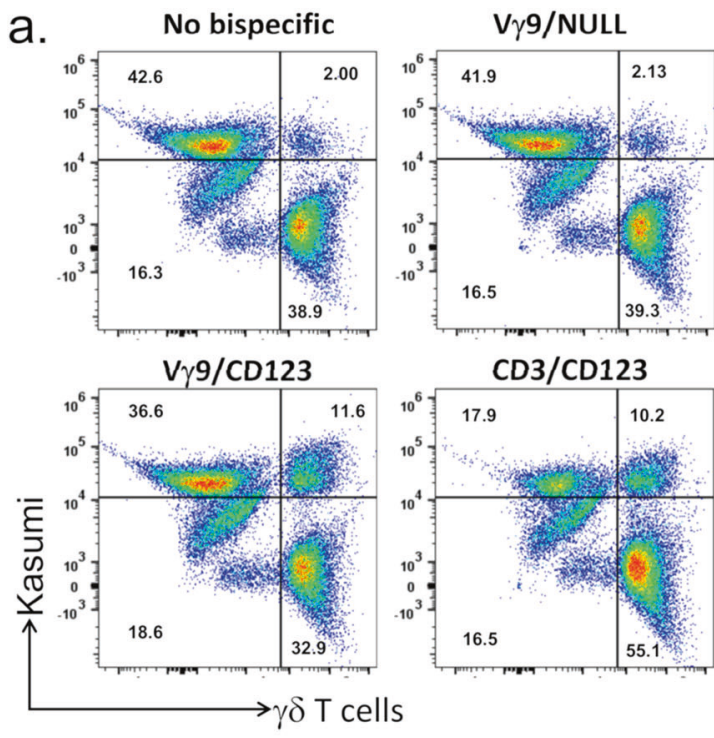

Fig. 2 V $\gamma 9 / C D 123$ bispecific antibody mediates selective recruitment, activation differentiation, and proliferation of $\mathrm{V} \boldsymbol{9}^{+} \boldsymbol{\gamma} \delta$ $\mathbf{T}$ cells. Cell trace green labelled enriched $\gamma \delta \mathrm{T}$ cells (effectors) were co-cultured with cell trace yellow labelled kasumi-3 cells (targets) at 1:1 ET ratio in the presence of $1 \mu \mathrm{g} / \mathrm{mL}$ of indicated bispecific antibody at $37^{\circ} \mathrm{C}$ for $1 \mathrm{~h}$. Cell-cell association was determined using flow cytometry and quantified as double positive cells in upper right quadrant of FACS plot (a). Numbers in quadrants indicate the frequency of respective population (a). b and $\mathbf{c}$ CFSE labelled Pan T-cells (effectors) from fresh PBMCs were co-cultured with Kasumi-3 cells (targets) at 1:1 ET ratio in the presence or absence of indicated

These data, thus, provide the proof of the concept that $\mathrm{V} \gamma 9$ / CD123 bispecific antibody can selectively activate and recruit $\mathrm{V} \gamma 9^{+} \gamma \delta \mathrm{T}$ cells to effectively kill tumor cells.

\section{V/9/CD123 bispecific antibody potently mediates activation, proliferation, and cytotoxicity by stimulating $\mathrm{V}_{\gamma} 9^{+} \mathrm{\gamma} \delta \mathrm{T}$ cell fraction among whole PBMCs}

To assess whether $\mathrm{V} \gamma 9 / \mathrm{CD} 123$ bispecific is capable of selective stimulation of $\mathrm{V} \gamma 9^{+} \gamma \delta \mathrm{T}$ cell fraction present in the whole PBMCs, we co-cultured whole PBMCs with CD123-expressing kasumi-3 cells in the presence or absence of $\mathrm{V} \gamma 9 / \mathrm{CD} 123$ and CD3/CD123 along with control bispecific antibodies. The frequency of ${\mathrm{V} \gamma 9^{+}}^{+}$or $\mathrm{V} \gamma 9^{-} \gamma \delta$ $\mathrm{T}$ cells (Pan $\mathrm{T}$ cells lacking $\mathrm{V} \gamma 9^{+} \gamma \delta \mathrm{T}$ cells) expressing activation markers CD69 and CD25 were determined by FACS analysis. Data presented in Fig. 4a, c show induction of surface expression of CD69 and CD25 by V $\gamma 9 / \mathrm{CD} 123$ bispecific antibody in the $\mathrm{V} \gamma 9^{+} \gamma \delta \mathrm{T}$ cell compartment, whereas CD3/CD123 activated both $\mathrm{V} \gamma 9^{+}$and $\mathrm{V} \gamma 9^{-} \mathrm{T}$ cell populations. Similarly, CFSE dilution, a measure of proliferation, was also very selective for $\mathrm{V} \gamma 9 / \mathrm{CD} 123$ bispecific antibody; it only induced proliferation of $\mathrm{V} \gamma 9^{+} \gamma \delta \mathrm{T}$ cells b.
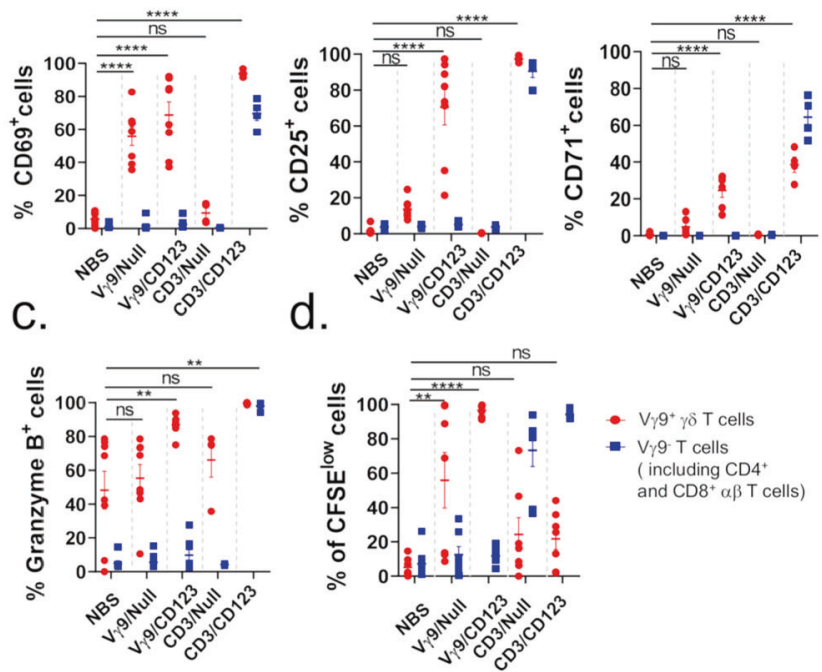

bispecific antibodies at $37^{\circ} \mathrm{C}$ for $72 \mathrm{~h}$. Scatter plot graphs mirror the mean $\left({ }^{+} \mathrm{SEM}\right)$ frequency of $\mathrm{V} \gamma 9^{+} \gamma \delta \mathrm{T}$ cells and $\mathrm{V} \gamma 9^{-} \gamma \delta \mathrm{T}$ cells (includes $\mathrm{CD}^{+}$and $\mathrm{CD}^{+} \mathrm{T}$ cells) that were positive for $\mathrm{CD} 69$ (left), CD25 (middle) and CD71 (right) surface expression (b), intracellular Granzyme B expression (c), and CFSE dilution (d). Red circle and blue square represent $\mathrm{V} \gamma 9^{+} \gamma \delta \mathrm{T}$ cells and $\mathrm{V} \gamma 9^{-} \mathrm{T}$ cells (includes $\mathrm{CD} 4^{+}$ and $\mathrm{CD} 8^{+} \alpha \beta \mathrm{T}$ cells), respectively. Each dot represent data from an individual donor. The $p$ values were calculated with a one-way ANOVA and Dunnett's multiple comparison test $(* p<0.05$, ** $p<$ $0.01, * * * p<0.001, * * * * p<0.0001$, and ns suggests $p>0.05)$. NBS No bispecific antibody.

(Fig. 4b). Conversely, the CD3/CD123 bispecific antibodies induce proliferation of $\mathrm{T}$ cells irrespective of $\mathrm{V} \gamma 9^{+}$cells (Fig. 4b). We further determined the ability of $\mathrm{V} \gamma \mathrm{g} / \mathrm{CD} 123$ bispecific antibody to eliminate exogenously added Kasumi-3 target cells among whole PBMCs. Our data suggest that although $\mathrm{V} \gamma 9 / \mathrm{CD} 123$ bispecific antibody only recruited and activated $\mathrm{V} \gamma 9^{+} \gamma \delta \mathrm{T}$ cells (a fraction of total $\mathrm{T}$ cells in the PBMC population), it mediated efficient target cell elimination, similar to CD3/CD123, which recruits and activates all pan-T cells (Fig. 4d). To strengthen the concept further, $\mathrm{V} \gamma 9^{+} \gamma \delta \mathrm{T}$ cell-depleted pan-T cells or total pan-T cells obtained from whole PBMCs were incubated in the presence and absence of bispecific antibodies at various concentrations and Kasumi-3 tumor cells (Supplementary Fig. S3). Selective binding of $\mathrm{V} \gamma 9 / \mathrm{CD} 123$ or $\mathrm{V} \gamma 9 / \mathrm{Null}$ bispecific antibodies is only shown when $\mathrm{V} \gamma 9^{+}$cells were present (Supplementary Fig. S3a). Cytotoxicity mediated by $\mathrm{V} \gamma$ 9/CD123 bispecific antibody was determined and is presented in Supplementary Fig. S3b, where no cytotoxicity was seen when $\mathrm{V} \gamma 9^{+} \gamma \delta \mathrm{T}$ cells were depleted (Supplementary Fig. S3b, left panel). On the other hand, the cytotoxicity of CD3/CD123 bispecific antibody with pan-T cells and pan-T cells depleted of $\mathrm{V} \gamma 9^{+} \gamma \delta \mathrm{T}$ cells was evident (Supplementary Fig. S3b, right panel). 
a.

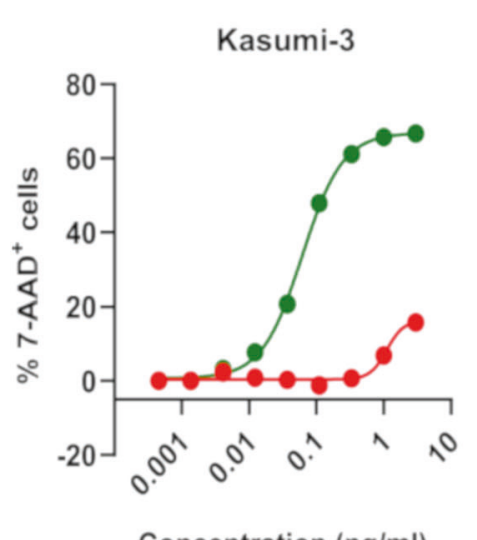

b.

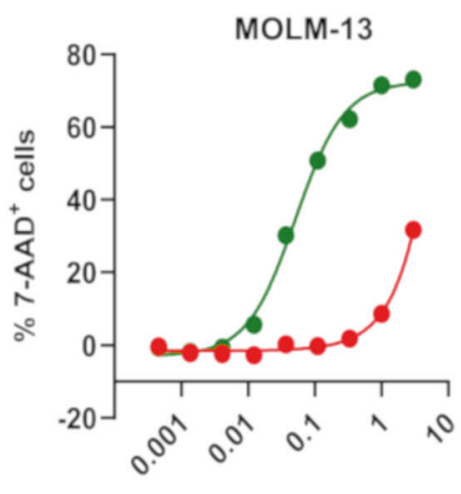

Concentration (ng/mL)
C.

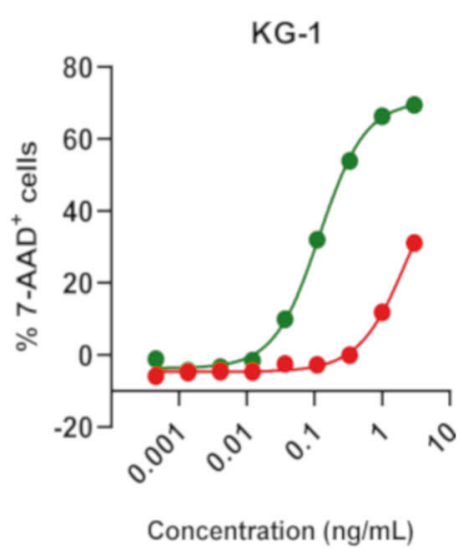

\section{- Vy9/CD123 bispecific Ab}

Fig. $3 \mathrm{~V} \gamma 9 / \mathrm{CD} 123$ bispecific mediated $\gamma \delta \mathrm{T}$ cell cytotoxicity against CD123-expressing tumour cell lines. Healthy donor PBMCs were cultured with Zoledronic acid+IL-2+IL-15 for 14 days, for selective expansion of ${\mathrm{V} \gamma 9^{+}} \delta \mathrm{T}$ cells. Day 14 PBMCs (effectors) were cocultured with CFSE-labelled target (Kasumi-3/MOLM-13/KG-1 cells) cells at ET ratio 1:1 (by normalizing the ET ratio to $\mathrm{V} \gamma 9^{+} \gamma \delta \mathrm{T}$ cell frequency in expanded PBMCs) in the presence of the indicated

\section{VY9/CD123 bispecific antibody efficiently induces cytotoxicity by stimulating $V \gamma 9^{+} \gamma \delta \mathrm{T}$ cell fraction among AML patient PBMCs}

Three approaches were adopted to assess the ability of antiTRGV9 targeting bispecific antibodies in redirecting $\mathrm{V} \gamma 9^{+}$ $\gamma \delta \mathrm{T}$ cells obtained from AML patients to kill tumor cells. In the first approach in vitro expended $\mathrm{V} \gamma^{+} \gamma \delta \mathrm{T}$ cells obtained from an AML patient were studied for cytotoxicity against Kasumi-3 cells, where V $\gamma 9 / \mathrm{CD} 123$ bispecific antibody mediated efficient cytotoxicity against CD123expressing Kasumi-3 cells (Fig. 4e). These data, thus, provide the proof of the concept that $\mathrm{V} \gamma 9 / \mathrm{CD} 123$ bispecific antibody can selectively activate and recruit $\mathrm{V} \gamma 9^{+} \gamma \delta \mathrm{T}$ cells from AML patients to kill tumor cells.

In the second approach, we assess the ability of $\mathrm{V} \gamma 9^{+} \gamma \delta$ $\mathrm{T}$ cells present in the AML patient PBMCs for elimination of AML blasts present within the PBMCs by culturing AML patient's whole PBMCs in the presence of $\mathrm{V} \gamma 9 / \mathrm{CD} 123$ for 8 days and counting the number of dead cells at the end of the culture. Since AML blasts are CD123-positive, they can potentially be targeted by $\mathrm{V} \gamma 9 / \mathrm{CD} 123$. The data depicted in Fig. 4f show that $\mathrm{V} \gamma 9 / \mathrm{CD} 123$ bispecific antibody, but not its null control, effectively mediated the elimination of endogenous blasts (represented by the increased fraction of dead cell compartments among the CD3 negative fractions) (upper row). Further, $\mathrm{V} \gamma 9 / \mathrm{CD} 123$ bispecific antibody selectively induced the proliferation of $\mathrm{V} \gamma 9^{+} \gamma \delta \mathrm{T}$ cells as measured by the frequency of $\mathrm{V} \gamma 9^{+} \gamma \delta \mathrm{T}$ cells among total T cells (Fig. 4f, concentration of $\mathrm{V} \gamma 9 / \mathrm{CD} 123$ or $\mathrm{V} \gamma 9 / \mathrm{Null}$ arm control bispecific antibodies for a period of 16-24 h. Target cell lysis was determined by 7-AAD staining on flow cytometry. Mean $\mathrm{EC}_{50}$ value of $\mathrm{V} \gamma 9 / \mathrm{CD} 123$ (green) bispecific mediated lysis of Kasumi-3 (0.46 pM, panel a), MOLM-13 (0.66 pM, panel b), and KG1 (1.25 pM, panel c) cell lines. KG1 cell line was sensitive for bystander cytotoxicity by the $\mathrm{V} \gamma 9 / \mathrm{Null}$ (red) bispecific.

lower row). The frequency of elimination of endogenous blasts seems to be synchronized with the proliferation of $\mathrm{V} \gamma 9^{+} \gamma \delta \mathrm{T}$ by $\mathrm{V} \gamma 9 / \mathrm{CD} 123$ bispecific. These data suggest that $\mathrm{V} \gamma 9 / \mathrm{CD} 123$ bispecific antibody can efficiently activate and recruit $\mathrm{V} \gamma 9^{+} \gamma \delta$ $\mathrm{T}$ cells from AML patients to kill endogenous AML blasts.

In the third approach, we spiked the AML patient PBMCs with DLL3-expressing SHP-77 cells in the presence or absence of V $\gamma$ 9/DLL3 bispecific antibody. Data depicted in Supplementary Fig. S4a show that V $\gamma 9$ /DLL3 bispecific antibody effectively mediated the elimination of exogenously added target cells. Further, V $\gamma 9 /$ DLL3 bispecific antibody mediates elimination of target cells even at low ET ratios, i.e., when one effector cell $\left(\mathrm{V} \gamma 9^{+}\right.$ $\mathrm{T}$ cells) is dominated by $5-10$ target cells. Similarly, $\mathrm{V} \gamma \mathrm{g} /$ DLL3 bispecific antibody induced the proliferation of $\mathrm{V} \gamma 9^{+} \gamma \delta \mathrm{T}$ cells (Supplementary Fig. S4b), as evident by the increase in the absolute numbers of recovered $\mathrm{V} \gamma 9^{+} \gamma \delta$ $\mathrm{T}$ cells. Taken together, our data suggest efficient and selective activation and induction of cytotoxicity mediated by $\mathrm{V} \gamma 9 / \mathrm{CD} 123$ bispecific antibody despite the presence of a low number of ${\mathrm{V} \gamma 9^{+}}^{+} \delta \mathrm{T}$ cells among total $\mathrm{T}$ cells in PBMC population in AML patients.

\section{$\mathrm{V}_{\gamma} \mathrm{9}^{+} \boldsymbol{\gamma} \delta \mathrm{T}$ cell selective redirection does not elicit cytokine storm compared to pan-T cell re-direction}

We compared V $\gamma 9 / \mathrm{CD} 123$ bispecific antibody with CD3/ CD123 antibody-induced cytokine production by whole PBMCs in the presence of Kasumi-3 cells and bispecific 
a.

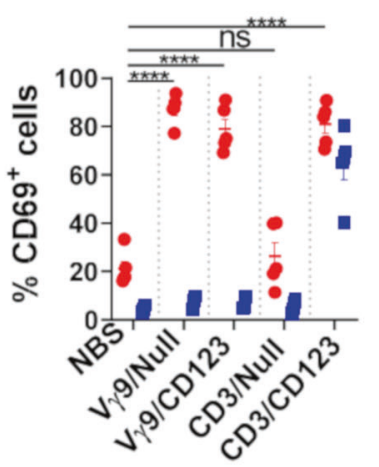

$\mathrm{V}_{\gamma} 9^{+} \gamma \delta \mathrm{T}$ cells b.

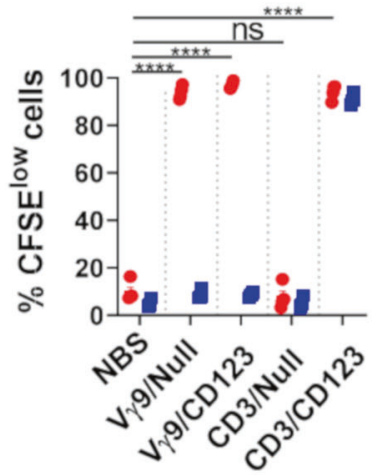

c.

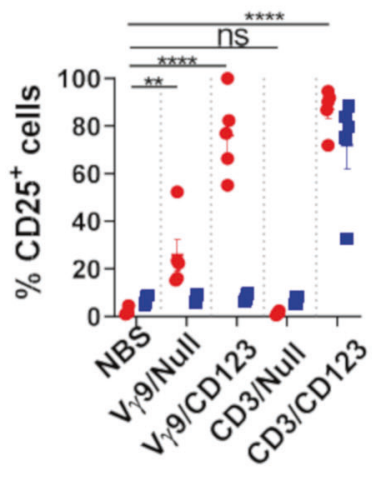

V $\gamma 9^{-}$T cells (including CD $4^{+} \& \mathrm{CD} 8^{+} \alpha \beta$ T cells)

e.

PBMCs (AML patients)

Kasumi-3

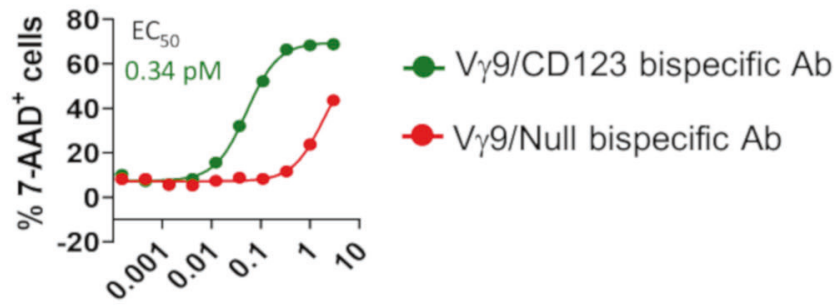

Concentration $(\mathrm{ng} / \mathrm{mL})$ d.

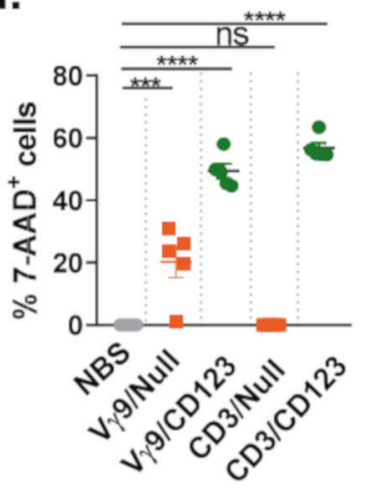

f.

Day 0

Day 8

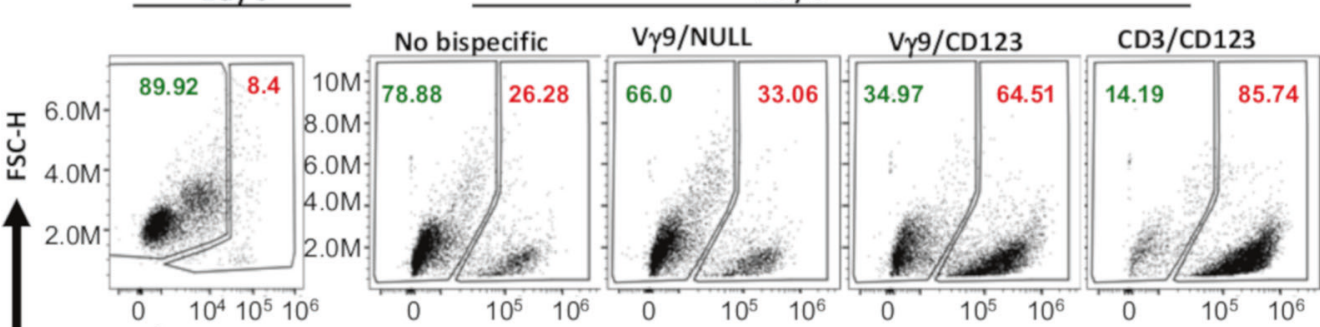

Live/Dead

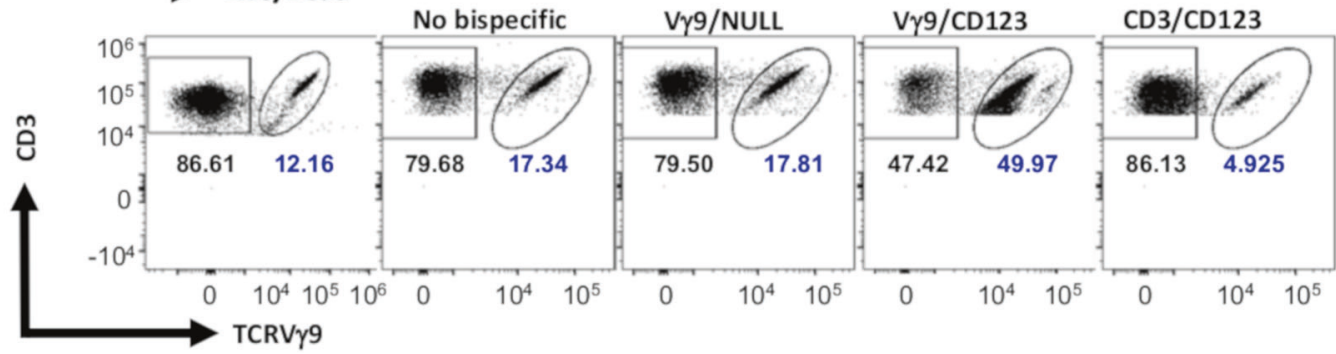

antibodies as described in "Materials and methods". From day 3 to day 8 of culture supernatants were analyzed for cytokine production. Data presented in Fig. 5a, b indicates that $\mathrm{V} \gamma 9 / \mathrm{CD} 123$ bispecific antibody induced much lower cytokines as compared to CD3/CD123 bispecific antibody, notably, IL-6 and IL-10 that are believed to the main players for cytokine storm in patients undergoing CD3-redirection immunotherapy. Based on these data, $\mathrm{V} \gamma 9$-redirection therapy is less likely to induce cytokine storm, and thus, it may help to broaden the therapeutic index. 
Fig. $4 \mathrm{~V} \gamma 9 / \mathrm{CD} 123$ bispecific antibody mediates selective activation, proliferation, and effector functions of $V \gamma \boldsymbol{9}^{+} \boldsymbol{\gamma} \delta \mathrm{T}$ cells among whole PBMCs. CFSE-labelled whole PBMCs from healthy individuals were cultured with Kasumi-3 cells in the presence or absence of the indicated bispecific antibodies at a concentration of $3 \mathrm{ng} / \mathrm{mL}$. Scatter plot graphs mirror the mean $( \pm \mathrm{SEM})$ frequency of $\mathrm{V} \gamma 9^{+} \gamma \delta$ $\mathrm{T}$ cells and $\mathrm{V} \gamma 9 \mathrm{TCR}$-depleted $\mathrm{T}$ cells that were positive for surface expression of CD69 (a), CFSE dilution (proliferation profile, b), CD25 (c), and the ability to eliminate exogenously spiked-in Kasumi-3 cells (cytotoxicity, d). The red circle and blue squares represent $\mathrm{V} \gamma 9^{+}(\gamma \delta)$ $\mathrm{T}$ cells and $\mathrm{V} \gamma 9$ TCR-depleted $\mathrm{T}$ cells, respectively. Each dot represents data from an individual donor. (e) AML patient PBMCs cultured in the presence of Zol+IL-2+IL-15 for 14 days (effectors) were cocultured with Kasumi-3 (target) cells at indicated concentrations of $\mathrm{V} \gamma 9 / \mathrm{CD} 123$ or $\mathrm{V} \gamma 9 / \mathrm{Null}$ arm control bispecific antibodies for $16-24 \mathrm{~h}$. Target cell lysis was assessed by $7-\mathrm{AAD}^{+}$staining on flow cytometry. Cytotoxicity values represented in (e) are after subtracting cell death from no bispecific (NBS) antibody controls. Mean $\mathrm{EC}_{50}$ value of $\mathrm{V} \gamma 9$ / CD123 (green) bispecific mediated lysis of Kasumi-3 (0.34 pM) was from two patients. The control $\mathrm{V} \gamma 9 / \mathrm{Null}$ (red) bispecific antibodies showed non-target specific cytotoxicity (e). f Whole PBMCs from AML patients were cultured either in the presence or absence of indicated bispecific antibodies for 8 days. The number in the representative FACS dot plots refers to live and dead cells among AML blasts (f, upper row) and the frequency of $\mathrm{V} \gamma 9^{-} \mathrm{CD} 3^{+}$and $\mathrm{V} \gamma 9^{+} \mathrm{CD} 3$ ${ }^{+}$cells among total $\mathrm{CD}^{+}$cells (f, lower row) on day 0 and 8 of the culture period. Representative data are means of values derived from two AML patients. The $p$ values were calculated with a one-way ANOVA and Dunnett's multiple comparison test. $(* p<0.05$, $* * p<$ $0.01, * * * p<0.001, * * * * p<0.0001$, and ns suggests $p>0.05) . N B S$ no bispecific antibody. a.
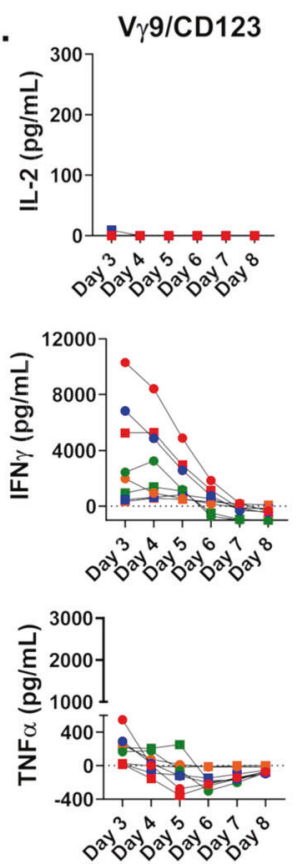
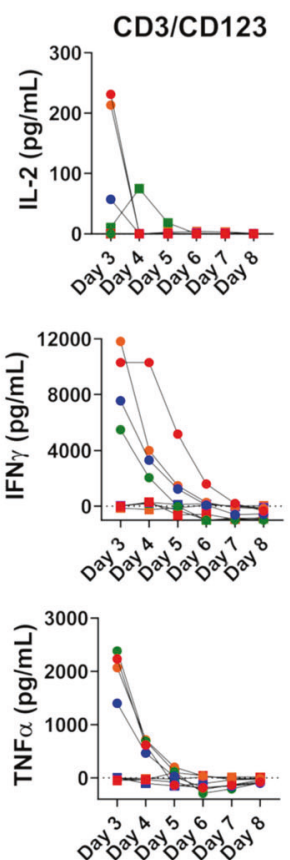

b.

$\mathrm{V} \gamma 9 / \mathrm{CD} 123$
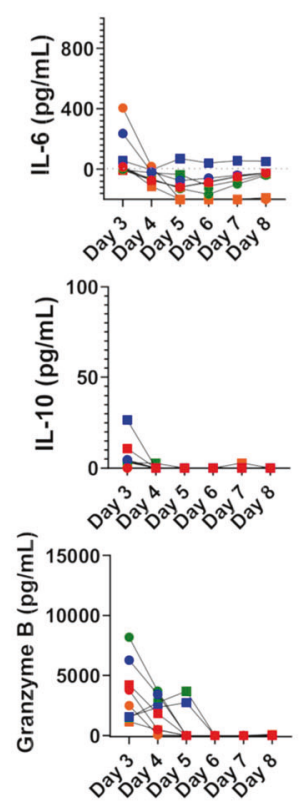

A xenograft NOD SCID mouse model with subcutaneously injected KG-1 tumor cell line and $\gamma \delta \mathrm{T}$ cells was used to evaluate the efficacy of $\mathrm{V} \gamma 9 / \mathrm{CD} 123$ bispecific antibody. Our data presented in Fig. 6a indicate that selective recruitment of $\mathrm{V} \gamma 9^{+} \gamma \delta \mathrm{T}$ cells by $\mathrm{V} \gamma 9 / \mathrm{CD} 123$ bispecific antibody induced significant tumor growth inhibition and efficacy as compared to control treatment. In parallel, to understand the innate homing capacity of activated $\mathrm{V} \gamma 9^{+} \gamma \delta \mathrm{T}$ cells to tumors, Dil dye-labelled $\gamma \delta \mathrm{T}$ cells were adoptively transferred into mice with established KG-1 tumors $\left(\sim 1000 \mathrm{~mm}^{3}\right)$, and $24 \mathrm{~h}$ post injection, harvested organs confirmed predominant homing of $\mathrm{V} \gamma 9^{+}(\gamma \delta) \mathrm{T}$ cells into the tumor, albeit a small fraction of these cells was also found in other organs in some mice (Fig. 6b). To further validate the utility of $\mathrm{V} \gamma 9 / \mathrm{CD} 123$ we performed pharmacokinetic (PK) study in C57BL/6 mice. PK analysis revealed $t_{1 / 2}$ values of $151 \pm 56 \mathrm{~h}(6.29 \pm 2.3$ day $)$ and $148 \pm 88 \mathrm{~h}(6.16 \pm 3.6$ day) for $\mathrm{V} \gamma 9 / \mathrm{CD} 123$ and $\mathrm{V} \gamma 9 / \mathrm{Null}$ bispecific antibodies, respectively, at a dose of $1 \mathrm{mg} / \mathrm{kg}$ and $120 \pm 12 \mathrm{~h}(5 \pm 0.5 \mathrm{day})$ and $120 \pm 31 \mathrm{~h}(5 \pm 1.2$ day $)$ respectively, at a dose of $10 \mathrm{mg} / \mathrm{kg}$, indicating a half-life suitable for redirection (Supplementary Fig. S5).

Fig. $5 \mathrm{~V} \gamma \boldsymbol{9}^{+} \boldsymbol{\gamma} \delta \mathrm{T}$ cell selective redirection does not elicit cytokine storm compared to Pan-T cell re-direction. Whole PBMCs from healthy individuals were cultured with kasumi- 3 cells in the presence or absence of the indicated bispecific antibodies $(3 \mathrm{ng} / \mathrm{ml})$ as described in Fig. 4. From day 3 of culture onward, $100 \mu \mathrm{L}$ of culture medium was removed every day from the wells, without disturbing the cells, and replenished with fresh medium until day 8 of culture. Cytokines were assessed from day 3 to day 8 cell culture supernatant.

a, b, Concentration of various cytokines or effector molecules in the culture supernatant of whole PBMCs stimulated with the indicated bispecific antibodies. Red, blue, green, and orange circles and squares represent PBMCs from four individual donors stimulated with indicated bispecific antibodies or NULL arm control bispecific antibodies, respectively. Representative data of $n=4$ donors from one independent experiment are shown here. 

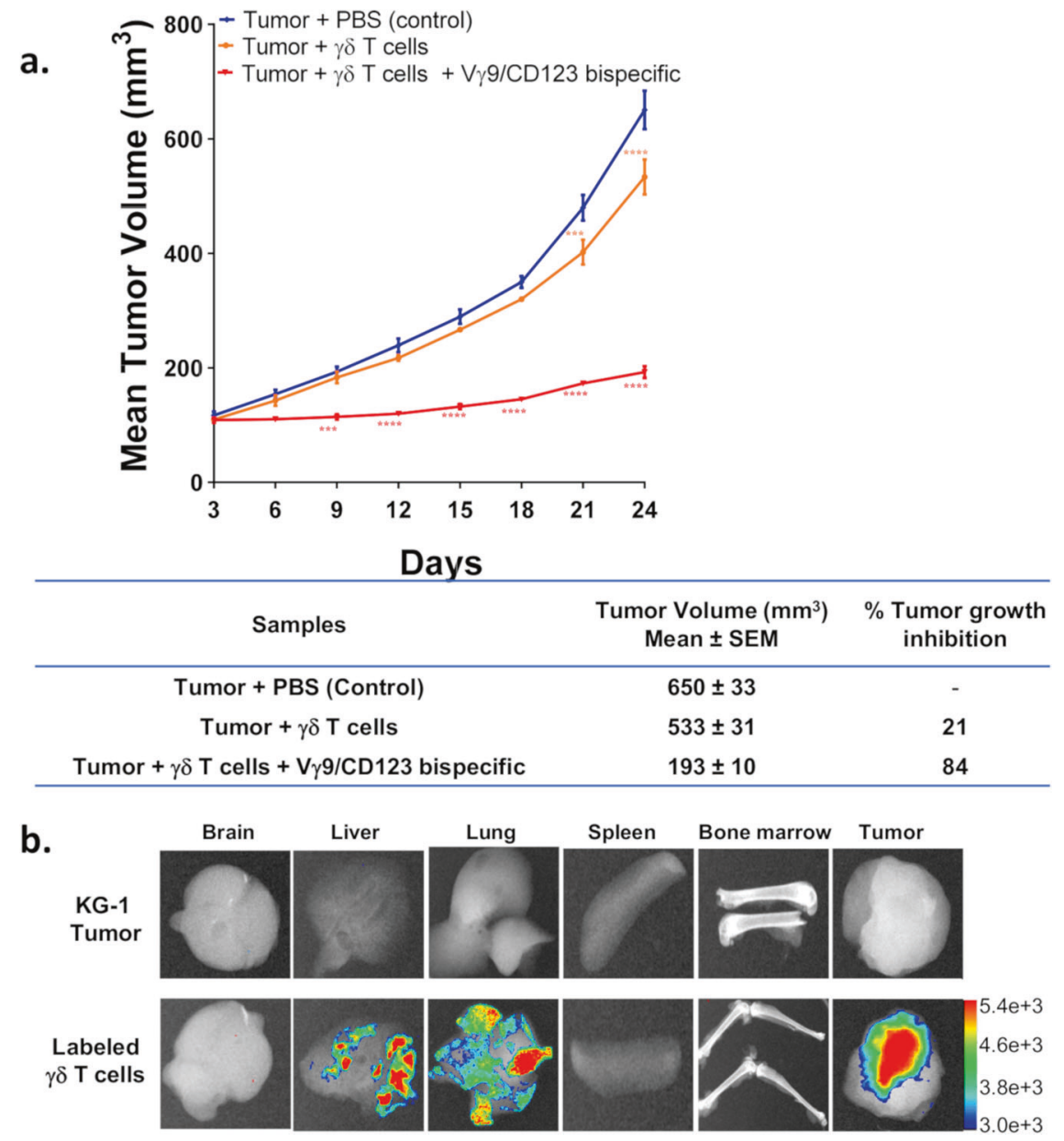

Fig. 6 Innate homing and $V \gamma 9 / C D 123$ bispecific mediated antitumor activity of $V \gamma 9^{+}(\gamma \delta)$ T cells in KG-1 xenograft model. a NOD-SCID mice were engrafted subcutaneously with KG-1 cells and were treated with PBS alone or expanded $\gamma \delta$ T cells alone or expanded $\gamma \delta \mathrm{T}$ cells $\mathrm{V} \gamma 9 / \mathrm{CD} 123$ bispecific antibody. Expanded $\gamma \delta$ were infused to the mice very week for four times. The table represents the percentage of tumor growth inhibition for all groups on day 24 of the experiment. b Fluorescence intensity in representative images refers to

Collectively, our data provide the in vivo proof of the concept that $\gamma \delta \mathrm{T}$ cells can efferently and rapidly home to tumors, and $\mathrm{V} \gamma 9 / \mathrm{CD} 123$ bispecific antibody can selectively activate and recruit $\mathrm{V} \gamma 9^{+} \gamma \delta \mathrm{T}$ cells to effectively kill tumor cells, and $\mathrm{V} \gamma 9 / \mathrm{CD} 123$ bispecific antibody could serve as a viable redirection approach for AML patients.

\section{Discussion}

Although CD3 $\mathrm{T}$ cell redirection-based immunotherapies have become effective treatments for B cell-related malignancies, they still remain to be validated for AML patients. Nonetheless, several $\mathrm{T}$ cell engagers (TCEs) are being tested in the clinic for AML $[6,21]$. Despite the promise of CD3-based TCEs, they manifest high toxicity and lack the abundance of adoptively transferred Dil dye-labelled $\mathrm{V} \gamma 9^{+} \gamma \delta$ $\mathrm{T}$ cells in various organs of mice with established KG-1 tumors $(\sim 1000$ $\left.\mathrm{mm}^{3}\right) . n=6$ mice for each group from a single experiment and 2-4 mice from two independent experiments. Statistical significance was calculated using two-way ANOVA followed by Bonferroni's post-test. $p \leq 0.05$ were considered as a statistically significant difference between groups $(* p<0.05, * * p<0.01, * * * p<0.001, * * * *<<0.0001$, and $\mathrm{ns}$ suggests $p>0.05$ ).

efficacy in many cases. This could be attributed to an intrinsic feature of these engagers that recruit and activate all kinds of $\mathrm{T}$ cells irrespective of the phenotype or lineage. For example, CD19 TCE, blinatumomab, activates Tregulatory cells that limit the activity of CD8 cytotoxic $\mathrm{T}$ cells to proliferate and effectively kill tumor cells [5], and increases $T$ regulatory cell numbers that correlate with nonresponsiveness to blinatumomab in ALL patients. Similarly, solitomab, an EpCAM TCE, showed serious adverse events with dose-limiting toxicities across all dose levels tested in Phase I clinical trials that prohibited dose escalation to the required therapeutic level [22]. Data from large number of trials with TCEs suggest that cytokine response syndrome is a key challenge for TCE therapies [23]. Activation of pan Tcells by anti-CD3 is likely the cause of massive of cytokine release seen in the patients. 
To address some of these issues we employed a strategy to recruit and activate a specific $\mathrm{V} \gamma 9 \mathrm{~V} \delta 2^{+}$circulating $\gamma \delta \mathrm{T}$ cell subset to target tumor cells. Our data suggest that $\mathrm{V} \gamma 9$ / CD123 bispecific antibody stimulated these cells appropriately to activate and induce cytotoxic response to AML blasts. Our in vivo imaging studies revealed that infused $\mathrm{V} \gamma 9^{+} \gamma \delta \mathrm{T}$ cells selectively colonized to tumors, which provides additional advantage for exerting efficacy in the presence of $\mathrm{V} \gamma 9 / \mathrm{CD} 123$ bispecific antibody, further favoring this subset. In addition, $\mathrm{V} \gamma 9 \mathrm{~V} \delta 2 \mathrm{~T}$ cells express DNAM-1 and are known to kill autologous AML blasts via the perforin/granzyme pathway by recognizing the ligands for DNAM-1 that are expressed by AML cells [24]. This function of $\mathrm{V} \gamma 9 \mathrm{~V} \delta 2 \mathrm{~T}$ cells may help to control tumor escape even when they lose target antigens.

Although selective recruitment of a subset of $\gamma \delta$ T cells is appealing, it is not clear whether engagement of a small population of $\gamma \delta \mathrm{T}$ cells would form sufficient contacts with tumor cells or induce effective anti-tumor response. The data presented here clearly demonstrate that $\mathrm{V} \gamma 9 / \mathrm{CD} 123$ bispecific antibody can efficiently recruit $\mathrm{V} \gamma 9^{+} \gamma \delta \mathrm{T}$ cells to form cell-cell conjugates of $\gamma \delta \mathrm{T}$ cells with tumor cells, selectively activates only ${\mathrm{V} \gamma 9^{+}}^{+} \delta \mathrm{T}$ cell and mediates cytotoxicity against tumor cells at low E:T ratios in vitro suggesting potent killing ability and that small numbers are sufficient to effectively eliminate tumor cells. As only a small population of $\mathrm{T}$ cells are activated, we anticipate this will result in overall lower cytokine release as compared to polyclonal $\mathrm{T}$ cell activation using CD3-redirection approaches. This concept is also validated in vivo where antiTRGV9/anti-CD123 bispecific antibody mediates $\gamma \delta$ T cell cytotoxicity against KG1 tumors and controls their growth.

One of the key questions is whether autologous $\mathrm{V} \gamma 9^{+} \gamma \delta$ $\mathrm{T}$ cells will be enough to eliminate the overwhelming population of AML blasts, and whether this subset of $\gamma \delta$ $\mathrm{T}$ cells from AML patients are fully functional. In this report, we first demonstrated that $\mathrm{V} \gamma 9 / \mathrm{CD} 123$ bispecific antibody selectively induced the proliferation of ${\mathrm{V} \gamma 9^{+}}_{\gamma} \delta$ $\mathrm{T}$ cells from AML patients, and second, we showed that V $\gamma$ 9/CD123 bispecific antibody efficiently activated and recruited $\mathrm{V} \gamma 9^{+} \gamma \delta \mathrm{T}$ cells to effectively kill endogenous AML blasts and AML tumor cell lines. In addition, antiTRGV9/anti-DLL3 bispecific antibody was effective at low ET ratios (1:8), suggesting bispecific antibody-mediated serial killing activity by $\gamma \delta \mathrm{T}$ cell from AML patients. Thus, we believe, despite the small number of $\mathrm{V} \gamma 9^{+} \gamma \delta \mathrm{T}$ cells compared to AML blasts, there are multiple ways that these cells could mount a productive immune response against overwhelmed blasts in AML patients.

Although the $\mathrm{V} \gamma 9^{+}$subset of $\gamma \delta \mathrm{T}$ cells could also serve as a good candidate for $\gamma \delta$ CAR-T cells, there are distinct advantages for redirecting these cells with $\mathrm{V} \gamma 9$ / CD123 bispecific antibody. First, $\gamma \delta \mathrm{T}$ cells are innate immune cells, $\gamma \delta$ CAR-T cells may not persist for very long in vivo as has been demonstrated recently, where $\gamma \delta$ CAR-T cell infusion resulted in limited persistence of these cells in animal models [25]. This may require multiple infusions and developing a large supply of the allogenic product of $\gamma \delta$ CAR-T cells. On the other hand, $\mathrm{V} \gamma$ 9/CD123 bispecific antibody can be easily dosed as frequently as needed to achieve optimal efficacy. Second, there is a clear safety advantage; in the case of toxicity induced by the $\mathrm{V} \gamma 9 / \mathrm{CD} 123$ bispecific antibody, it can easily be mitigated by simply withdrawing or adjusting the dose of the drug as opposed to $\gamma \delta$ CAR-T cells where the only option would be to manage the patient with complicated procedures or develop a product that can easily be eliminated from the system. Third, as outlined elegantly by Cummins et al., the general limitation of CAR-T cells in AML is that the targeting myeloid antigens may lead to prolonged myeloablation, which is not clinically tolerable [26]. Fourth, CAR-T cells may directly contribute to target cell antigen loss, resulting in low antigen density. In a recent study, it was demonstrated that CAR-T cells decreased antigen density on target cells through the mechanism of trogocytosis, a process by which targeted antigens are transferred to the CAR-T cells [27]. This process not only decreased antigen density on the target cells, but also makes CAR-T cells positive for the tumor antigen; once the CAR-T cells obtain the target antigen, they themselves can become targets of CAR-T fratricide, potentially contributing to lack of persistence. Finally, the prime advantage for the bispecific antibody approach is the ease and cost of treatment for AML patients. Although some of the limitations of $\gamma \delta$ CAR-T cells could potentially be mitigated by further development of the CAR-T field, it would be difficult to predict if there is a clear winner until clinical data comparing these two approaches become available.

In summary, we present a mechanism to recruit and activate the $\mathrm{V} \gamma 9^{+}$subset of $\gamma \delta$ T cells to mediate cytotoxicity against AML blasts. Selective recruitment of $\gamma \delta$ T cells, particularly activation of only a small subset of $\gamma \delta \mathrm{T}$ cells, should only lead to overall low cytokine release. As recruited cells will be highly potent and readily penetrate tumor tissues, this combined with the low overall cytokine production should lead to a broader therapeutic index. Furthermore, such a $\gamma \delta$ T cell targeted therapy would present a major advantage for most AML patients.

Acknowledgements We thank the members of Janssen R\&D and Syngene for technical support with the production and profiling of antibodies, and Sam Wu for epitope/paratope mapping.

Author contributions RG, SS, and IG conceived the presented idea. $\mathrm{RG}, \mathrm{VC}, \mathrm{BR}$, and MRH carried out the experiments and RG, VC, BR, $\mathrm{MRH}$, and IG performed the analysis. RG, VC, BR, and IG wrote the 
manuscript. All co-authors discussed the results, provided critical feedback, and contributed to the final manuscript.

\section{Compliance with ethical standards}

Conflict of interest When this research was conducted, all co-authors were employees of either The Janssen Pharmaceutical Companies of Johnson and Johnson or Syngene International Ltd. RG, SS, and IG own shares of Johnson and Johnson Inc and are co-inventors of provisional patent applications.

Publisher's note Springer Nature remains neutral with regard to jurisdictional claims in published maps and institutional affiliations.

Open Access This article is licensed under a Creative Commons Attribution 4.0 International License, which permits use, sharing, adaptation, distribution and reproduction in any medium or format, as long as you give appropriate credit to the original author(s) and the source, provide a link to the Creative Commons license, and indicate if changes were made. The images or other third party material in this article are included in the article's Creative Commons license, unless indicated otherwise in a credit line to the material. If material is not included in the article's Creative Commons license and your intended use is not permitted by statutory regulation or exceeds the permitted use, you will need to obtain permission directly from the copyright holder. To view a copy of this license, visit http://creativecommons. org/licenses/by/4.0/.

\section{References}

1. Dohner H, Weisdorf DJ, Bloomfield CD. Acute myeloid leukemia. N Engl J Med. 2015;373:1136-52.

2. Loghavi S, Zuo Z, Ravandi F, Kantarjian HM, Bueso-Ramos C, Zhang L, et al. Clinical features of de novo acute myeloid leukemia with concurrent DNMT3A, FLT3 and NPM1 mutations. J Hematol Oncol. 2014;7:74.

3. Lu S, Wang J. Homoharringtonine and omacetaxine for myeloid hematological malignancies. J Hematol Oncol. 2014;7:2.

4. Gentles AJ, Newman AM, Liu CL, Bratman SV, Feng W, Kim D, et al. The prognostic landscape of genes and infiltrating immune cells across human cancers. Nat Med. 2015;21:938-45.

5. Duell J, Dittrich M, Bedke T, Mueller T, Eisele F, Rosenwald A, et al. Frequency of regulatory $\mathrm{T}$ cells determines the outcome of the T-cell-engaging antibody blinatumomab in patients with Bprecursor ALL. Leukemia. 2017;31:2181-90.

6. Campagne O, Delmas A, Fouliard S, Chenel M, Chichili GR, Li $\mathrm{H}$, et al. Integrated pharmacokinetic/pharmacodynamic model of a bispecific CD3xCD123 DART molecule in nonhuman primates: evaluation of activity and impact of immunogenicity. Clin Cancer Res. 2018;24:2631-41.

7. Gill SI. How close are we to CAR T-cell therapy for AML?. Best Pr Res Clin Haematol. 2019;32:101104.

8. Di Lorenzo B, Simões AE, Caiado F, Tieppo P, Correia DV, Carvalho $\mathrm{T}$, et al. Broad cytotoxic targeting of acute myeloid leukemia by polyclonal Delta One T cells. Cancer Immunol Res. 2019;7:552-8.

9. Oberg HH, Peipp M, Kellner C, Sebens S, Krause S, Petrick D, et al. Novel bispecific antibodies increase gammadelta T-cell cytotoxicity against pancreatic cancer cells. Cancer Res. 2014;74:1349-60.

10. de Bruin RCG, Veluchamy JP, Lougheed SM, Schneiders FL, Lopez-Lastra S, Lameris R, et al. A bispecific nanobody approach to leverage the potent and widely applicable tumor cytolytic capacity of Vgamma9Vdelta2-T cells. Oncoimmunology. 2017;7: e1375641.

11. Bonneville M, O'Brien RL, Born WK. Gammadelta T cell effector functions: a blend of innate programming and acquired plasticity. Nat Rev Immunol. 2010;10:467-78.

12. Vantourout P, Hayday A. Six-of-the-best: unique contributions of gammadelta $\mathrm{T}$ cells to immunology. Nat Rev Immunol. 2013;13:88-100.

13. Sebestyen Z, Prinz I, Déchanet-Merville J, Silva-Santos B, Kuball J. Translating gammadelta $(\gamma \delta) \mathrm{T}$ cells and their receptors into cancer cell therapies. Nat Rev Drug Discov. 2020;19:169-84.

14. Wesselborg S. Selective activation of gamma/delta $+\mathrm{T}$ cell clones by single anti-CD2 antibodies. J Exp Med. 1991;173:297-304.

15. de Bruin RCG, Lougheed SM, van der Kruk L, Stam AG, Hooijberg E, Roovers RC, et al. Highly specific and potently activating Vgamma9Vdelta2-T cell specific nanobodies for diagnostic and therapeutic applications. Clin Immunol. 2016;169:128-38.

16. Oberg HH, Kellner C, Gonnermann D, Peipp M, Peters C, Sebens $\mathrm{S}$, et al. Gammadelta $\mathrm{T}$ cell activation by bispecific antibodies. Cell Immunol. 2015;296:41-9.

17. Oberg HH, Kellner C, Gonnermann D, Sebens S, Bauerschlag D, Gramatzki M, et al. Tribody [(HER2)2xCD16] is more effective than trastuzumab in enhancing gammadelta $\mathrm{T}$ cell and natural killer cell cytotoxicity against HER2-Expressing cancer cells. Front Immunol. 2018;9:814.

18. Kunkele KP, Wesch D, Oberg HH, Aichinger M, Supper V, Baumann C. Vgamma9Vdelta2 T Cells: Can We Re-Purpose a Potent Anti-Infection Mechanism for Cancer Therapy? Cells 2020;9:829.

19. Oberg HH, Janitschke L, Sulaj V, Weimer J, Gonnermann D, Hedemann $\mathrm{N}$, et al. Bispecific antibodies enhance tumorinfiltrating $\mathrm{T}$ cell cytotoxicity against autologous HER-2expressing high-grade ovarian tumors. $\mathrm{J}$ Leukoc Biol. 2020;107:1081-95.

20. Kiladjian JJ, Visentin G, Viey E, Chevret S, Eclache V, Stirnemann J, et al. Activation of cytotoxic T-cell receptor gammadelta $\mathrm{T}$ lymphocytes in response to specific stimulation in myelodysplastic syndromes. Haematologica. 2008;93:381-9.

21. Al-Hussaini M, Rettig MP, Ritchey JK, Karpova D, Uy GL, Eissenberg LG, et al. Targeting CD123 in acute myeloid leukemia using a T-cell-directed dual-affinity retargeting platform. Blood. 2016;127:122-31.

22. Kebenko M, Goebeler ME, Wolf M, Hasenburg A, SeggewissBernhardt R, Ritter B, et al. A multicenter phase 1 study of solitomab (MT110, AMG 110), a bispecific EpCAM/CD3 T-cell engager $(\mathrm{BiTE}(\mathrm{R}))$ antibody construct, in patients with refractory solid tumors. Oncoimmunology. 2018;7:e1450710.

23. Labrijn AF, Janmaat ML, Reichert JM, Parren P. Bispecific antibodies: a mechanistic review of the pipeline. Nat Rev Drug Disco. 2019;18:585-608.

24. Gertner-Dardenne J, Castellano R, Mamessier E, Garbit S, Kochbati E, Etienne A, et al. Human $\mathrm{V} \gamma 9 \mathrm{~V} \delta 2 \mathrm{~T}$ cells specifically recognize and kill acute myeloid leukemic blasts. J Immunol. 2012;188:4701-8.

25. Rozenbaum M, Meir A, Aharony Y, Itzhaki O, Schachter J, Bank I, et al. Gamma-Delta CAR-T Cells Show CAR-Directed and Independent Activity Against Leukemia. Front Immunol. 2020;11:1347.

26. Cummins KD, Gill S. Will CAR T cell therapy have a role in AML? Promises and pitfalls. Semin Hematol. 2019;56:155-63.

27. Hamieh M, Dobrin A, Cabriolu A, van der Stegen SJC, Giavridis $\mathrm{T}$, Mansilla-Soto J, et al. CAR T cell trogocytosis and cooperative killing regulate tumour antigen escape. Nature. 2019;568:112-6. 